\title{
Structural performance of precast foamed concrete sandwich panel subjected to axial load
}

\begin{abstract}
In this paper, experimental and simple analytical studies on the structural behavior of Precast Foamed Concrete Sandwich Panel (PFCSP) were reported. Full-scale tests on six PFCSP panels varying in thickness were performed under axial load applications. Axial load-bearing capacity, load-deflection profiles, load-strain relationships, slenderness ratio, loaddisplacement, load-deformation, typical modes of failure and cracking patterns under constantly increasing axial loads were discussed. Nonlinear Finite Element Analysis (FEA) using LUSAS software to investigate the structural behavior of PFCSP was contacted. The computed ultimate strength values using American Concrete Institute equation (ACI318) and other empirical formulas developed by pervious researchers which applicable to predict the ultimate strength capacity of sandwich panels were compared with the experimental test results and FEA data obtained; therefore, very conservative values resulted, a significant agreement with the FEA data that presented a high degree of accuracy with experiments and an increase in slenderness function.
\end{abstract}

Keyword: $\quad$ Precast Foamed Concrete Sandwich Panel (PFCSP); Foamed Concrete (FC); Finite Element Analysis (FEA); Axial load; Load-deflection curves; Loadstrain relationships; Slenderness ratio; Strength capacity of PFCSP 
